\title{
Albert Tomàs Monsó «Vostre cos és de verí replet»: caràcter i gènesi del maldit català
}

\begin{abstract}
The purpose of this paper is to propound a hypothesis concerning the genesis and development of the genre maldit in medieval Catalan poetry ( $14^{\text {th }}$ and $15^{\text {th }}$ centuries), considering the rhetorical and grammatical treatises, the genre assignment of rubrics and its practice. The maldit is a type of moral, satirical form, which aims to attack through satire a specific person or group. In their definitions, the treatises place maldit and the literary concept of satire under the scope of sirventès. Also, they point out a difference between general and particular maldit or maldit especial. This hypothesis argues that the term maldit especial refers to satirical poems about both male and female individuals, based on this definitions but also on genre rubrics and literary ressemblance with other genres, such as the cantigas descarnho e de mal dizer. Keywords Medieval Catalan Poetry; Literary Genres; Maldit; Sirventes; Rhetorical and Grammatical Treatises.
\end{abstract}

\section{$\rightarrow$ 1. Introducció}

Qualsevol aproximació als gèneres literaris medievals, per específica que sigui, es troba de seguida amb l'escull gairebé insalvable de la inestabilitat de codificació d'aquests mateixos gèneres en el seu temps. En el cas català, l'aparició dels tractats retòrics i gramaticals de finals del XIII i principis del xIv comportà la fixació d'uns principis, però també una lectura retroactiva sobre la producció anterior, aplicant esquemes moderns sobre uns textos que, en la majoria dels casos, tenien ja entre cent i dos-cents anys d'història (Paden 200o). Els tractats foren, amb tot, decisius, perquè condicionaren la pràctica poètica posterior d'una manera notable, especialment a l'àrea occitanocatalana, definint - decidint - amb més o menys precisió allò que era o no era un determinat gènere. Amb la prevenció necessària que aquest ordre de coses requereix, i a la llum de noves dades, l'objectiu d'aquest article és el de proposar una hipòtesi per al naixement i desenvolupament del gènere del maldit en la poesia catalana dels segles XIV i XV.

El maldit és un tipus de composició moral, que té com a objectiu l'atac contra una persona concreta o contra un collectiu, normalment associada per la crítica moderna al blasme misogin. Tot i així, aquesta mateixa crítica ha destacat encertadament que la majoria de maldits conservats no fan atacs generals contra el gènere femení, com s'esdevé habitualment en la literatura misò- gina, sinó que presenten la particularitat d'atacar una dona concreta i determinada.

Cal destacar, entre la bibliografia existent, la generosa contribució d'Isabel de Riquer a l'estudi d'aquest gènere català, amb diversos treballs (1996, 1996-97 i 2005), així com la de Robert Archer (1996a i 1996b). Tots dos són coautors de l'única antologia publicada de maldits (Archer \& Riquer I. 1998), punt de partida per a qualsevol aproximació al gènere, i els seus treballs constitueixen el gruix de la recerca que s'hi ha dedicat. En aquest article, s'exposaran primer les idees d'Isabel de Riquer i Robert Archer i, posteriorment, es proposarà una lectura complementària del maldit i la seva gènesi a partir d'una possible relació amb el sirventès. Es tindran en compte la pràctica poètica, les definicions dels tractats retòrics i gramaticals i l'assignació de rúbriques als manuscrits.

\section{$\rightarrow$ 2. A la recerca d'un origen: la mala canso}

El maldit català ha estat considerat l'evolució directa de la mala canso trobadoresca, una variant de la canso amorosa canònica que vitupera la dompna a causa del desamor, el desengany o la manca de mercè envers el trobador. Aquestes injúries mantenen els esquemes feudals de la canso filtrats per la visió escolàstica de l'amor: la mala dompna és frívola, infidel, promíscua, ingrata, inconstant, superba, enganyosa; si és que no considerem, directament, que femina nulla bona est. 
L'origen del terme mala canso es remunta a les cançons de gesta franceses i, segons Dietmar Rieger (1976: 316), en la lírica amorosa s'oposa a la fórmula bona canso, que apareix amb molta més freqüència a la tradició occitana. Així, dit grosso modo, la bona canso lloa la bona dompna, aquella que complau el trobador, i la mala canso blasma la mala dompna, aquella que, naturalment, no el complau (Rieger D. 1976: 303-318; Rieger A. 1992; Riquer I. 1996-97).

L'esquema de Dietmar Rieger (bona dompnabona canso / mala dompna-mala canso) és sens dubte funcional i permet explicar la presència d'una bona i una mala dompna a la poesia d'amor trobadoresca. No obstant això, no es pot descartar que l'expressió bona canso tingui un caràcter retòric, com a record del bene dicendi llatí, i que no condicioni tant el contingut com la qualitat del discurs adjectivat. A tall d'exemple, llegim un fragment de la vida de Peire Ramon de Tolosa: «e saub ben trobar e cantar; e fetz bonas cansos» (Boutière \& Schutz 1950: 230), de la de Guilhem Figueira: «E saup ben trobar e cantar» (Boutière ¿ Schutz 1950: 171), o de la de Guirardó lo Ros, que «fon cortes e ben chantanz» (Boutière \& Schutz 1950: 189). A més, l'ús del qualificatiu $b o$ no està restringit al gènere de la canso. La vida del trobador Peire de Busssignac ens diu que «Trobaire fo de bons sirventes, de reprendre las donnas que fazian mal e de reprendre los sirventes d'En Bertran de Born» (Boutière \& Schutz 1950: 224). Raimon de Tors, per la seva banda, va escriure un «Mieg serventes bo» (v. 31) contra les sogres («A totz maritz mand e dic», BdT 410.4, Riquer M. 1975: 1394-1395).

Quant a la mala canso, es troba documentada per primera vegada a la Chanson de Roland, en dues ocasions, vinculades a la guerra. En la preparació de la batalla de Roncesvalls, Roland interpella Oliver i l'esperona al combat: «Pur sun seignor deit hom susfrir destreiz $\mid \mathrm{E}$ endurer e granz chalz e granz freiz, | Si.n deit hom perdre e del quir e del peil. | Or guart chascuns que granz colps i empleit, | Male cançun de nus dite ne seit!» (vv. 1010-1014; Roncaglia 1947: 93-94). Més tard, quan Marsili contraataca amb la seva host, Roland torna a prendre la paraula: «Jo i ferrai de Durendal, m'espee | E vos, compainz, ferrez de Halteclere. | E tantes teres les avum nos portees! |
Tanes batailles en avum afinees! | Male chançun n'en deit estre cantee» (vv. 1462-1466; Roncaglia 1947: 93-94).

Fora de les cançons de gesta franceses no trobem cap altre exemple poètic que faci referència a la mala canso. Si ens hem de cenyir als testimonis conservats, en l'àmbit de la lírica cortesa la mala canso neix i és vigent exclusivament a les vidas i les razos. La vida del trobador Gui d'Ussel, en una versió única que es conserva al cançoner $P$, incorpora una razo per al poema «Si be.m partetz, mala dompna, de vos». Es tracta d'una canso de deseiximent o de despit, en què el trobador pren comiat de la dama en no ser correspost. La razo afegida a $P$ i que introdueix el poema diu així (Boutière \& Schutz 1950: 136-137):

\footnotetext{
poiz ditz:

\begin{abstract}
Si be $m$ partetz, mala dompna, de vos, non es raison q'eu me parta de chan ni de sollatz, qe faria semblan q'eu fos iratz d'aiso don soi joios. ben fui iratz, mas ara me [re]pen, car emprez ai del vostr' e[n]segnamen com posca leu camjar ma volontat; per q'era chan [d'aiso] don ai plorat
\end{abstract}

Donc la dompna, per la respon[sa] qe En Gui fetz, anet et tollc a marit un chevalier de Catalogna qe avia nom Renardon, et det conjat a Gui d'Usel e.l parti de se, digan q'ella no.l faria son drutz hom qe non fos cavalier[s]. Donc Gui d'Usel fetz la mala chanson, pois qe ac facha la tenson. E la mala chanson qe fetz

El poema (BdT 194.19) fa joc amb un debat previ del mateix trobador amb el seu cosí Elies d'Ussel sobre la conveniència de ser marit o restar en la posició d'amant de la dama, de nom Gidas de Mondus («Ara.m digatz vostre semblant», BdT 194.2). Gidas, que segons la vida de Gui d'Ussel era neta de Guillem de Montpeller i cosina germana de la reina d'Aragó, finalment apartà Gui d'Ussel del seu servei, i com a conseqüència d'això aquest entrà en contacte amb la cort de Maria de Ventadorn, amb qui establí un segon debat poètic derivat del mateix afer ("Gui d'Ussel, be-m pesa de vos», BdT 295.1). També Peire d'Ussel, germà de Gui, hi tornà («Fraire en Gui, be.m platz vostra cansos», BdT 361.1), tal com ens n'informa la razo de $P$ a continuació (Boutière é Schutz 1950: 138): 
Pois qe Gui d'Usel ac facha la mala chanson q'eu vois ai dicha e comenza enaisi:

Si be $m$ partetz, mala dompna, de vos

—en la qal el blasmet so qe avia lausat, _En Peire d'Usel, sous cosis, per repenre Gui d'Usel, fetz aqesta cobla e mandet li:

Fraire en Gui, be.m platz vostra cansos, qe dissetz mal lei qe lauzes a[n]tan; se.n dissetz mal, ella no.i a nul dan, che cavalier deu me[i]l amar qe vos; et s'ella.us fe conven nesciamen, ella.us a frait aconsilladamen. Ben deu esser per aiso perdonat, pois ella se conoc de sa foldat.

La peça de Gui d'Ussel gaudí d'una difusió notable (Rieger A. 1992) i fou contrafeta, de maneres més o menys explícites, per diversos trobadors (Riquer M. 1975: 1017; Riquer I. 2005: 145-146). Tres noms presenten per a nosaltres un especial interès: Raimon de Miraval, Peire Vidal i Gaucelm Faidit, també relacionat amb Maria de Ventadorn i Elies d'Ussel, amb qui intercanvià un diàleg poètic. En dues ocasions més apareix escrit el terme mala canso. La primera és al si d'una razo múltiple de Ramon de Miraval (Boutière \& Schutz 1950: 291-292), on als cançoners $E, P$ i $R$ el biògraf connecta tres peces d'aquest trobador («Amors me fai chantar et esbaudir», BdT 406.4; «Enquer non a guaire», BdT 406.27; «S'ieu en chantar soven», BdT 406.38) i fa servir l'expressió per introduir uns versos extrets del poema «Estat ai en gran sazo» de Peire Vidal (BdT 364.21):

Quan Miravals auzit la novela del mal que'ela [la dama] avia fag e del mal que totas gens dizion d'ela, e que Peire Vidals n'avia faita una mala chanso d'ela: Estat ai una gran sazo, en la cal el dis en una cotbla:

Molt ai mon cor felo per leis, que mala fo; que per un comte ros m'a gitat a bando.

Ben par que Loba es, quant ab comte s'enpres e.s part d'emperador c'a faita sa lauzor per tot lo mon saber; mas qui men non ditz ver, Miraval si fo sobre totz plus dolens.
L'última vegada que queda documentada la mala canso és a la razo del poema « $\mathrm{Si}$ anc nuills hom, per aver fin coratge» de Gaucelm Faidit (BdT 167.52), en la versió conservada als cançoners $E, N^{2}, P$ i $R$ (Boutière \& Schutz 1950: 121):

E no tarzet gaire, quan se'n foron tornat, qu'En Gauselms venc, e sa moiller li comtet tot lo fait. Gauselms, quant ho auzit, fo si dolens qu'el volc morir per so qu'el crezia qu'ela no volgues be si no a lui. E per so qu'ela al sieu leit l'avia colgat, en fo el mais dolens; don el fes per aquesta razo una mala chanso, la cals comensa:

Si anc nuls hom per aver fin coratge,

si com vos ausirets. Et aquesta fo la derriera chanso qu'el fes.

Per fer-se una idea més exacta de la dimensió que va tenir la mala canso, val la pena aturar-se en la circulació del terme als cançoners trobadorescos. Dels nou manuscits $(A, B, E, I, K, P, R$, aII i $\left.a^{1}\right)$ que reporten la vida de Gui d'Ussel, només $P$ (f. 48rv) copia les razos que designen la mala canso. En el cas de Raimon de Miraval, sobre un total de deu $\left(A, B, E, H, I, K, P, R, a I I\right.$ i $\left.a^{1}\right)$ només tres $(E$, f. 200; $P, \mathrm{f} .39 \mathrm{v}$ i $R \mathrm{f} . \mathrm{I}^{\mathrm{d}}$ ) són els que ens donen notícia de la mala canso de Peire Vidal. Finalment, dels nou manuscrits $\left(A, B, E, K, N^{2}, P, p, a\right.$ i $\left.a I I\right)$ que transmeten la vida de Gaucelm Faidit, en són quatre que fan servir la denominació mala canso (E, f. 194; P, f. $39^{2}$; $R$ f. I $^{\text {i }} N^{2}$ f. 25 ). Deixant de banda $N^{2}$, que està datat a la Itàlia del segle Xvi, la prova de l'existència de la mala canso queda circumscrita a un moment determinat —el moment de la redacció de les vidas del cercle poètic entorn de Gui d'Ussel i Maria de Ventadorn- i transmesa en tres cançoners del segle XIV, que són $E$ (ff. 194 i 20o), $P$ (ff. 39v, $39^{2}$ i 48rv), i $R$ (f. $I^{\mathrm{d}}$ ).

Dietmar Rieger (1976: 303-318) fou el primer a abordar de manera específica la mala canso i formulà dues idees clau. La primera, que no s'ha d'entendre com un gènere independent sinó que forma part d'un conjunt de subgèneres, juntament amb el comiat, on el trobador s'acomiada de l'amor, i la canso de canvi, on anuncia una nova estimada, que orbiten al voltant de la canso canònica. Més concretament, considera que la mala canso ha de ser llegida com una modalitat específica del que ell anomena cançons de comiat. La segona idea 
que defensa Dietmar Rieger és que aquest tipus de poesia manté punts de contacte amb el sirventès i els gèneres de lluïment retòric per la seva naturalesa dialèctica. En paraules de Valeria Bertolucci Pizzorusso (1993: 112) la mala canso "può sfociare anche in aperto vituperio, con conseguente salto nel genere sirventese». Ja hem vist el cas de "Qan lo doutz temps d'abril» (BdT 332.1) de Peire de Bussignac, definit a la vida com a trobador de «bons sirventes, de reprendre las donnas que fazian mal e de reprendre los sirventes d'En Bertran de Born» (Boutière \& Schutz 1950: 224). La primera vida de Marcabrú ens informa que «Trobaire fo dels primers c'om se recort. De caitivetz vers e de caitivetz serventes fez, e dis mal de las femmas e d'amor» (Boutière \& Schutz 1950: 211). Guilhem Ademar va escriure un sirventès contra les dones que no accepten l'amor dels lleials («Ieu ai ja vista manhta ley», BdT 203.7) i Bernart de Venzac un contra l'amor deshonest («Lanquan cort la doussa bia» BdT 71.1a). De la mateixa manera, es conserven alguns debats o tensos en què un trobador adopta una posició de lloança i l'altre, de blasme, com el que es va produir entre Peire d'Alvernha i Bernart de Ventadorn -Peire d'Alvernha hi defensa l'amor i Bernart de Ventadorn el condemna i ataca les dones- ("Amics Bernartz de Ventadorn», BdT 323.4), o el cèlebre Maldit bendit de Cerverí de Girona - primer exemple de maldit rubricat-, on Cerverí construeix un blasme de tipus general o sàtira de collectius sobre el patró de les formes dialèctiques i la retòrica de la confrontació, basades en la tradició de la laudatio i la vituperatio llatina (Cabré M. 1999; Monson 1981: 139-140; Cantavella 1988-89), que, al seu torn, es troben a l'origen del gènere del sirventès, com ha demostrat la bibliografia recent (Asperti 2002 i 2005).

Aquest conjunt de referències assenyala, doncs, que en època trobadoresca el blasme de dones i el sirventès no pertanyien sempre a dues esferes del tot diferenciades. D'altra banda, el terme maldit és extremadament rar en la poesia trobadoresca. Tot i que dir mal d'algú o d'alguna cosa és una expressió d’allò més estesa, el terme maldit només apareix una vegada en l'inventari lèxic de Suzanne Thilioer-Méjean sobre el corpus de poemes satírics i morals (1973: 175), com apareix també una única vegada el verb maldir, menys que altres expressions d'odi i injúria com escarnir (quatre vegades), azirar (disset vegades) i blasmar (vint-i-sis vegades).

\section{$\rightarrow$ 3. El sirventès i el maldit: una proposta d'interpretació}

La mala canso de Gui d'Ussel va tenir una àmplia difusió -el poema es conserva en una vintena de manuscrits (Riquer M. 1975: 1017; Rieger A. 1992)— i els tòpics trobadorescos habituals de denúncia de la vulneració del codi de la fin'amors per part de la dama es van transmetre de manera clara de la poesia trobadoresca a la catalana - Isabel de Riquer (2005) en fa un repertori molt complet. Per la seva banda, el maldit català està fortament relacionat amb el blasme d'una dama, com a contraexemple negatiu de la canso, fet que l'apropa a la mala canso de Gui d'Ussel i els seus derivats (Rieger A. 1992; Riquer I. 2005). Tanmateix, Martí de Riquer, fidel a les paraules dels mateixos trobadors - vegeu els versos citats de Peire d'Ussel-, denominà la mala canso de Gui d'Ussel «canción de maldecir» (Riquer M. 1975: 1017) i anys a venir traduí el terme per «canción mordaz» (Riquer M. 1995: 98-103), conscient de la possibilitat que «las denominaciones de chantar, chansó y tal vez chan, que hemos visto antes, tuvieran un alcance muy general (como hoy "poesía") y que ello permita que un sirventés pueda ser llamado al mismo tiempo chansó o chan» (Riquer M. 1971: 195).

En una mirada de conjunt a les literatures de l'Europa meridional, cal tenir present l'existència anàloga de les cantigas d'escarnho e de mal dizer galaicoportugueses. A través de la sàtira personal i punyent, les cantigas apellaven directament a un destinatari a través d'un vocatiu, normalment descobert i a l'inici de la peça. Aquest tipus de composicions es basaven en l'escarnho, és a dir, la sàtira, i tenien com a objectiu el mal dizer, és a dir, el blasme (Videira 2002). Molt properes als nostres maldits, alludien principalment homes. S'han conservat, però, algunes d'aquestes cantigas adreçades a dones, de rerefons amorós, amb un clar component satíric i jocós. En dos casos - dues cantigas satíriques contra dones de Fernan Paez de Talamancos-, fins i tot, han estat copiades als manuscrits a les seccions d'escarnho i no pas a les d'amor, un senyal inequívoc que les restriccions conceptuals modernes no es corresponen sempre 
de manera exacta amb la realitat dels gèneres literaris medievals (Bertolucci Pizzorusso 1993).

Com passa en les cantigas d'escarnho e maldi$z e r$, el blasme i la sàtira són també els dos factors principals del sirventès personal. Aquesta mena de sirventès, conreada per Guillem de Berguedà (Riquer M. 1971; Grifoll 2017), es basava en l'atac ad hominem sense palliatius a una persona concreta, habitualment amb finalitats polítiques d'algun tipus, l'objectiu del qual era aconseguir el descrèdit a través d'expressions d'odi o de befa. A partir de finals del segle XII, el sirventès personal convisqué amb una vessant culta del gènere, iniciada per Bertran de Born i culminada per Cerverí de Girona, mitificadora de la cavalleria i enaltidora dels valors feudals, on la política i la moral prengueren un pes més important $\mathrm{i}$ el to dels poemes passà a ser més elevat (Asperti 2002 i 2005).

El maldit català comparteix la sàtira grollera, burlesca, o en alguns casos juganera, amb el sirventès personal. I, per bé que, a jutjar pels testimonis conservats, el maldit contra les dones fou el més practicat, ens han arribat alguns exemples del segle Xv de maldits contra homes. És el cas del poema de Simó Pastor «Per divulgar la pratica dampnada» (RAO 129.1), el de Pere Miquel Carbonell «Vos, en Galant, vergonya teniu poca» (RAO 30.8) o l'anomenat cicle contra Bernat Fajadell, ara Bernat del Bosc (Rodríguez Risquete 2002). Cal destacar també el cas de Guillem de Masdovelles, que va escriure un comiat contra el seu senyor Guerau de Cervelló («Reunabblament, per gran desconaxença», RAO 101.14) i va maldir fins a quatre vegades la sort d'haver-lo conegut.

La primera cobla de «Per divulgar la pratica dampnada» de Simó Pastor (RAO 129.1) ens dona una imatge del to $i$ el tipus de sàtira propis del gènere:

\footnotetext{
Per divulgar la pratica dampnada

que tu, vilment, cascun jorn exercites -

bordells, taulers e tavernes visites,

corroborant la vida raprovada -

me só dispost, e no poch voluntari,

en declarar tos crims espressament

perche d'uymés no sies fictament

entre les gents entès per lo contrari.

(vv. 1-8; Archer 1996a: 108)
}

D’altra banda, una observació de les rúbriques dels manuscrits catalans pot aportar llum a la qüestió. Existeixen tres poemes catalans de mitjans del segle $\mathrm{xv}$, copiats a tres manuscrits diferents, que satiritzen homes i que porten el terme maldit a la rúbrica: són els anònims «No us vullau metre.n amar» (RAO 0.93; Barcelona, Biblioteca de l'Ateneu Barcelonès, ms. 1, ff. 82v-84r) i «No.m sé si s'és mon servell» (RAO 0.92; BA, ms. 1, ff. 84v-85r; Saragossa, Biblioteca General Univesitaria de Zaragoza, ms. 210, f. 108v) i el poema de Simó Pastor «Per divulgar la practica dampnada», (RAO 129.1; BA, ms. 1, ff. 153r-154r; Barcelona, Biblioteca de Catalunya, ms. 10, ff. 183r-183v), ${ }^{1}$ del qual acabem de llegir un fragment. Tots tres es conserven al ms. 1 de l'Ateneu. Els dos anònims, copiats l'un darrere l'altre, van seguits d'una tercera peça també rubricada maldit ( $\mathrm{Pus}$ que vostre fonament», RAO 0.116; BA, ms. 1, ff. 85v-87r). És un maldit contra una dona. Així doncs, aquest manuscrit conté, copiats seguidament, tres poemes satírics, amb característiques i to similars, que a ulls del copista no es diferencien pel fet d'estar destinats a un home o a una dona. Heus aquí uns versos de «No.m sé si s'és mon servell» (RAO o.92), que pertanyen a les anomenades Cobles de la panadera:

$$
\begin{aligned}
& \text { Homanàs e de vil farga, } \\
& \text { bort fill no sab hom de qui, } \\
& \text { empatxes de borzaguí; } \\
& \text { mal hi diu la falda larga: } \\
& \text { com va lo camí, embarga; } \\
& \text { ffastig n'age lo carrer, } \\
& \text { com un mascarat farrer, } \\
& \text { no li romp la cervellera. } \\
& \text { La panadera. } \\
& \text { (vv. 19-27; Archer 1996a: 113) }
\end{aligned}
$$

Es poden contraposar, per exemple, a la sisena estrofa del maldit anònim contra una dona del ms. 1 de l'Ateneu tot just esmentat («Pus que vostre fonament», RAO 0.116 ):

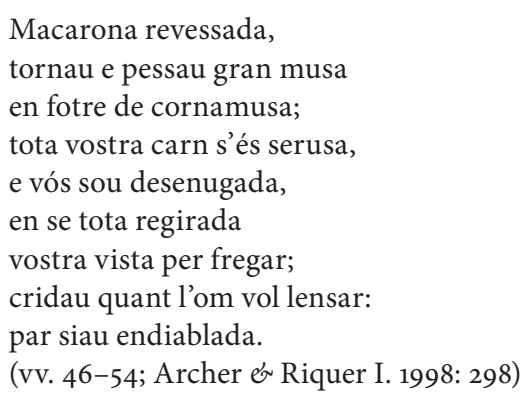

1. Editats conjuntament per Robert Archer (1996a); els dos anònims abans per Martí de Riquer (1986). 
L’atac ad hominem aquí ja no es fonamenta només en els tòpics trobadorescos de despit envers la dama, sinó que s'ha tenyit de la sàtira grollera pròpia del sirventès. Així doncs, sembla raonable proposar una aproximació al maldit català que tingui en compte també la influència del sirventès, entenent que, en el terreny de la pràctica poètica, no va existir de manera establerta una restricció de gènere literari per a la burla, en funció de si la víctima satiritzada era masculina o femenina. Allò que a la tradició trobadoresca era el sirventès personal i satíric, a la tradició catalana va passar a ser anomenat maldit, com a conseqüència de l'especialització del sirventès en la seva forma més culta, és a dir, en els models de Bertran de Born i Cerverí de Girona. La sàtira personal, més aviat joglaresca, va quedar-ne exclosa i relegada al maldit, o més específicament, a allò que els tractats van anomenar maldit especial.

\section{$\rightarrow$ 4. Els tractats, la fixació i la posteritat}

Es fa necessari, en parlar d'idees literàries en vulgar a la poesia catalana medieval, de parar atenció a la codificació dels tractats retòricogramaticals. La inclinació dels poetes catalans al seguiment de les preceptives és un element determinant per comprendre el desenvolupament posterior de la pràctica poètica.

Des del moment en què veieren la llum les Razos de trobar de Ramon Vidal de Besalú, primera preceptiva coneguda, a la primera meitat del XIII, fins a la segona meitat del s. XIV, època en què cessà la producció d'aquest tipus de textos, un total de set tractats retòrics recolliren una definició més o menys àmplia del maldit $i$ tots ells, sense excepció, ho van fer dins l'àmbit del sirventès. Són les Regles de trobar, de Jofre de Foixà; la Doctrina de compondre dictats, d'autor anònim; les Leys d'amors, de Guillem Molinier, en les seves diverses redaccions en prosa i en vers, i que inclouen les Flors del Gay Saber; el Doctrinal de trobar de Ramon de Cornet, reportat i comentat pel Glossari al Doctrinal de trobar de Raimon de Cornet de Joan de Castellnou, també autor del Compendi de la conaxença dels vicis que poden esdevenir en los dictatz del Gay Saber, i, en darrer lloc, el Torcimany, de Lluís d'Averçó. ${ }^{2}$

2. Aquests tractats es troben recollits en un mateix
De l'observació directa dels tractats es desprèn que, almenys des de finals del XIII i fins a principis del $\mathrm{xv}$, el maldit o acte de mal dir no era concebut com un gènere per se; més aviat s'entenia com una matèria o tema dels quals podia tractar el sirventès, amb el mateix valor que els fets bèllics o els assumptes polítics. Així ho expressa Ramon Llull al capítol 48 del Blaquerna, «De Valor»: «Sol per açó son entrat en pensament con faça .i. novell serventesch en lo qual diga mal de valor e de sos servidors» (Galmés 1935-54: I, 235), o la vida de Guillem de Berguedà: «Bons sirventes fetz, on disia mals als uns e bens als altres» (Boutière \& Schutz 1950: 153). Vegem la definició de Jofre de Foixà a les Regles de trobar (Marshall 1972: 57):

Si tu comences a far un sirventesch de fayt de guerra o de reprendimen o de lausors, no-s conve que.y mescles raho d'amor; o si faç canço o dança d'amor, no·s tayn que.y mescles fayt d'armes ne maldit de gens, si donchs per semblances no o podíets aportar a raho.

La Doctrina de compondre dictatz diu: «Si vols far sirventez, deus parlar de fayt d'armes, e senyaladament o de lausor de senyor o de maldit o de qualsque feyts qui novellament se tracten» (Marshall 1972: 95). Finalment, les Leys d'amors en la primera redacció en prosa (Gatien-Arnoult 1841-43: 340) - de la qual depenen les Flors del gay saber i les posteriors redaccions, així com el Compendi de Castellnou i el Torcimany de Lluís d'Averçó-: «Sirventes [...] deu tractar de reprehensio. $\mathrm{O}$ de maldig general. Per castiar los fols e los mavatz. O pot tractar quis vol. Del fag d'alquna guerra».

Una idea bàsica que recullen tots els tractats és que el sirventès, fent ús del mal dir, pot blasmar o castigar els malvats del món, amb possibilitat de lloar els virtuosos per mostrar-los com a exemple (Doctrina) o educar els ignorants (Leys, segona redacció en prosa). En submergir-nos en la matèria moral de la poesia trobadoresca - $\mathrm{i}$ també de la posttrobadoresca-, la porositat entre gèneres aflora: vers i sirventès es confonen amb

manuscrit (Barcelona, Biblioteca de Catalunya, ms. 239), compilat a finals del s. XIV, llevat de les Leys d'amors (Tolosa de Llenguadoc, Archives de l'Académie des Jeux Floraux mss. 500.006 i 500.007; Barcelona, Arxiu de la Corona d'Aragó, ms. 13 de Sant Cugat) i el Torcimany de Lluís d'Averçó (El Escorial, Biblioteca del Monasterio del Escorial, ms. M. I. 3). 
facilitat. No obstant això, preval una certa noció que el vers és un mitjà per vehicular una veritat epistemològica i divina. En canvi, el Doctrinal de Raimon de Cornet afirma que el sirventès «de mals pot parlar | que vers no ho deu far» (Casas Homs 1969: 197). Mentre que el vers transmet un precepte moral, doncs, el sirventès critica els vicis humans.

En darrer lloc, les preceptives evidencien una forta preocupació per la diferència entre el maldit general -dedicat a collectius socials-i el maldit especial -dedicat a persones concretes, sense especificar-ne el gènere-, fins al punt que el maldit especial és codificat com a vici. Els tractats més antics diuen poc a propòsit d'això. Les Regles esmenten el «maldit de gens» (Marshall 1972: 57), però no el condemnen ni van més enllà en la segregació entre maldit general i especial. La Doctrina parla només de «maldit», però el contraposa a la lausor de senyor (Marshall 1972: 95-97). Per la seva banda, el Compendi de Castellnou i el Torcimany reconeixen com a vici el maldit especial al costat de la sobrelloança. Així, queda reforçada la idea que el maldit no era $a$ priori un atac misogin - si bé es va especialitzar en aquest àmbit-, sinó que s'ha d'entendre en el marc de la poesia moral de censura personal que abastava també els atacs contra homes i que calia evitar tant com la sobrelloança a un senyor o senyora determinats.

Una vegada més, és la primera redacció de les Leys aquella que fixa el terme i el codifica per als preceptistes posteriors. Vegem què diuen del sirventès les Flors del Gay Saber (Anglade 1926: 70):

Tractans de maldig jeneral

Per xastiar cells que fan mal,

O de fayts mantas vetz de guerra

Que.s deu far en alcuna terra.

Hereu del sirventès moral de sàtira de collectius i comparable amb els cants satírics francesos d'aquesta mateixa mena d'autors com Rutebeuf o Moniot, el «maldit de gens» de què parla Jofre de Foixà quedà fixat com a maldit general a la primera meitat del XIV, essent el clergat el grup més assenyalat per aquest tipus de poesia. Pere Tresfort va escriure un sàtira contra la classe governant $i$ particularment la cúpula eclesiàstica, que plena d'orgull i avarícia desatén les seves obligacions («Gran carrech han huy tuyt l'om de paratge»,
RAO 181.2). Existeixen, encara, dues peces més de la primera meitat del segle $\mathrm{XV}$ que satiritzen el clergat. Es tracta d' $"$ Ans de molt temps veureu los confessors», de Lluís de Requesens (RAO 145.1), i d'«Estant ratret e d'enuig fatiguat», de Joan Berenguer de Masdovelles (RAO 103.67). Aquests dos poemes espigolen imatges i tòpics de la tradició anticlerical, present a la poesia trobadoresca durant la croada contra els albigesos i represa al segle XIII a propòsit del conflicte entre gibellins i angevins (Torró 2009: 63).

Ramon Savall, a «De mal saber, ab verinós coratge» (RAO 167.1), fa una allusió crítica a les dones, que són tractades com grup social al costat de pagesos, mercaders, prínceps, menestrals, ciutadans, etc. El poema «Aquestes velles vils mardoses», de Joan Berenguer de Masdovelles (RAO 103.22), és un altre exemple de sàtira de collectius:

$$
\begin{aligned}
& \text { Aquestes velles vils mardoses } \\
& \text { ja no les pusch mes comportar: } \\
& \text { tant son cruzels ez anugoses } \\
& \text { en tot quant fan ne poden ffar! } \\
& \text { (vv. 1-4; Aramon i Serra 1938: 70) }
\end{aligned}
$$

Notem com el poema, que continua en el mateix to i que està rubricat «Maldit contre les velles, ffet per Johan Berenguer de Masdovelles, a compas de dança» (Aramon i Serra 1938: 70), no ataca el gènere femení, sinó només les velles, per causes que no tenen res a veure amb el desamor. Com a resposta, Guillem de Masdovelles censura el seu nebot per aquest blasme contra les «vellas» (v. 1), «totes, en jeneral» (v. 3), que Guillem, pel fet de ser, ell també, «vielhs» (v. 1), defensa (Aramon i Serra 1938: 72):

\footnotetext{
Per qu'ieu suy vielhs, en favor de les vellas responch que vos, nabotz, usatz trop mal d'aysi blesmar totes, en jeneral, seguos appar en vostres cobles bellas: car jes no son totes contrerioses ha joventut ni.l joy d'emor complir, ans trobarets vellas qui fan venir a bona cort les jovens argulloses.
}

Parallelament al maldit general es configura el maldit especial, tot i que els tractats no l'esmenten, i si ho fan és només com a vici, per tal com no ha de ser una forma acceptada; no vol dir això que no es practiqués. El primer que fa aflorar el 
maldit especial en un tractat $-i$ per tant li reconeix l'existència- és Joan de Castellnou (Casas Homs 1969: 123):

malditz specials es quant hom en serventes o en autre dictat ditz mal d'alcuna certa persona. Car hom en sos dictats no deu specifficar lunya persona, ni deu dir paraules tals per qu.hom certa persona entenda quan en son dictat pauza aytal maldig. No diem ges qu.hom no puesca retrayre alcun Mal dits d'alcunas personas en general; mas [f. 46] que certa persona no sia nomanada ni designada; coma de renoiers, de mercaders, de borczes, de jutges, d'advocats o encara de comtes o d'autres baros o de Reys o de princeps. $\mathrm{E}$ en aysi de trops autres, e en aquest cas nengu no s'ho deu en mal tener si hom pausa alcun Mal ditz en general en son dictat. Car aytals Maldigs ha hom acostumatz de dire per xastiar e no per envega ni detraccio, ni per far ni per dar injuria ad home.

Segons l'òptica de Castellnou (en essència, també la de les Leys), la crítica de collectius és acceptada en tant que càstig moralitzant i exemplificant; no ho és, però, l'atac ad hominem injustificat $i$ injuriós, basat en enveges o conflictes estrictament personals que desvirtuen la crítica. Tot i la censura de Castellnou, però, la reprensió o càstig personal era més que corrent fins ben entrat el segle xv: el poema satíric de Francesc Ferrer «Aveu lexat ut re mi fa sol lla» (RAO 61a.1), pertanyent al cicle contra Bernat del Bosc, està acompanyat per una anotació molt deteriorada al marge inferior de la pàgina del manuscrit (Saragossa, BUZ, ms. 210, f. 107v.), que diu així: «malvat [...] Qui pora de ses erros [...] castigar». Segons Castellnou, l'atac no és exclusiu a la dona, sinó a «ad home»o "certa persona», expressió que amaga una crítica al maldit especial i que contrasta significativament amb l'«alcunas personas en general» de més amunt, referint-se a la sàtira de collectius.

Per la seva banda, el Torcimany, en un afany d'interpretar a la menuda el text de les Leys, afirma que el maldit especial no és honest - una vegada més sense especificar que es tracti d'un blasme misogin - i estableix que el sirventès o bé tracta de fets de guerra o bé fa reprensió de vicis a través del maldit general, ${ }^{3}$ però no ambdues coses a la vegada (Casas Homs 1956: 83-86):

3. La interpretació del Torcimany es deu, possiblement, al fet que Lluís d'Averçó sembla llegir amb valor excloent la partícula «o» que utilitzen les Flors del Gay Saber. sirventés deu tractar de una d'aquestes dues cosas, ço es, o de mal dit general, no pas especial, con no.s deu fer, per ço com no es bo ne honest a dir mal de negú especialment ne asenyalada, com semblant manera de mal dir mes es difamació que no castich, e com mal dir se deja fer per castigar aquelhs qui mal fan, e no per difamació deu-se fer aytal manera de mal dit dictat apelhat sirventés de fetz de guerra, e en aquest pas en aytal manera de sirventés se deuen metre paraulas garreras, e totas formas faent be a proposit de guerra.

Així doncs, segons la tractadística el maldit s'ha d'entendre com una variant del sirventès determinada pel seu contingut, al mateix nivell que la poesia política d'actualitat o la bèllica. Amb el pas del temps, cristallitzà una diferenciació entre maldit general - sàtira de collectius - i maldit especial - sàtira personal-; aquesta cristallització deuria estar influïda alhora per la pràctica poètica i, mentre que el maldit general era acceptat, el personal fou sempre condemnat.

Recapitulem. En aquest article es proposa que el maldit català no s'ha d'entendre com un gènere exclusivament misogin, ja que no fa distincions entre un destinatari masculí o femení. Així, es té en compte l'opinió de les preceptives, que emmarquen el maldit dins l'esfera del sirventès, el gènere trobadoresc que habitualment vehiculava les dues característiques principals del maldit: el blasme i la sàtira. Els tractats més tardans diferencien el maldit general del personal en funció de si la víctima és una persona concreta o un collectiu i condemnen com a vici el maldit contra persones concretes o maldit especial. En base a això, es proposa que, en l'àmbit de la poesia catalana, el maldit especial pugui ser entès com una derivació del sirventès personal, com a conseqüència de l'especialització del sirventès en la seva vessant més culta i elevada, seguint el model de Bertran de Born. Això no treu que el maldit contra dones fos més practicat, ni tampoc que els tòpics de la mala canso de Gui d'Ussel i de tants altres poemes trobadorescos en què el trobador es dirigeix a la dama en termes de despit per no ser correspost no puguin ser, també, a l'origen d'alguns dels maldits catalans conservats.

Considerar el maldit català des de l'òptica del sirventès ofereix nombrosos avantatges. Permet explicar l'existència de sirventesos trobadorescos 
contra dones, en sintonia amb les cantigas d'escarnho e maldizer, així com de les sàtires de collectius i els maldits catalans del segle xv escrits contra homes i rubricats igual que els maldits misògins. De la mateixa manera, aquesta hipòtesi integra perfectament les explicacions dels tractats retòrics i gramaticals, que fan una descripció unívoca d'aquest gènere controvertit per naturalesa, l'objectiu del qual va definir Ausiàs March a «Volgra ser nat cent anys o pus atràs» (RAO 94.127):

e lo mal hom deu ser cridat ab trompa per ço que mi e l'altre no engan: tants són aquells qui per bons hòmens van que, difamats, cessaria llur pompa.

(XLI, vv. 13-16; Bohigas 2000: 161-162)

\section{$\rightarrow$ 5. Apèndix}

A continuació s'ofereix un llista dels maldits catalans que porten rúbrica, numerats segons el RAO de J. Parramon (1992), i a partir de l'íncipit tal com apareix en les edicions de referència:

«No·m sé si s'és mon servell», anònim (RAO 0.92) «No us vullau metre.n amar», anònim (RAO 0.93) «Pus que vostre fonament», anònim (RAO o.116) "Pus havets bondat despesa», Joan Basset (RAO 14.17) «Vós qui sabeu de la tortra.l costum», Ausiàs March (RAO 94.128)

«Diats, mi-doncs: cuydau-vos que-us servescha», Guillem de Masdovelles (RAO 101.2)

"Ja no veyra mj-doncs que pus la blan», Guillem de Masdovelles (RAO 101.6)

«Pus ma'avets ffayt a tan gran fallimen», Guillem de Masdovelles (RAO 101.13)

«Aquestes velles vils mardoses», Joan Berenguer de Masdovelles (RAO 103.22)

"Ara conech sso que no conexia", Joan Berenguer de Masdovelles (RAO 103.24)

"Anuig mostrau aver que.us vulla be», Joan Berenguer de Masdovelles (RAO 103.60)

«Molt vos sou tart, dona reguoneguda», Joan Berenguer de Masdovelles (RAO 103.93)

«Per que.xi car, dona, ves mi teniu», Joan Berenguer de Masdovelles (RAO 103.14)

«Pus dau raho a mi, de mal perlar», Joan Berenguer de Masdovelles (RAO 103.126)

«Pus no·us dech res, ¿per què-m dieu que.us pach?», Joan Berenguer de Masdovelles (103.30)

«Tan me pinet, dona, que no pusch pus», Joan Berenguer de Masdovelles (RAO 103.161)
«Lliurada-us sou a mi no per amor», Pere Joan de Masdovelles (RAO 104.3)

«Temps és estat que m'anàveu pastar», Pere Joan de Masdovelles (RAO 104.5)

«Per divulgar la pratica dampnada», Simó Pastor (RAO 129.1)

Altres textos no rubricats que són indubtablement maldits es podrien afegir a aquest catàleg rudimentari — de fet, la bibliografia ja els ha tractat com a tals (Riquer I. 1996; Archer 1996a; Archer-Riquer I. 1998). Per exemple, el poema XLVII («Bé.m meravell com l'aire no s'altera», RAO 94.19) d'Ausiàs March, El canviador («Pus que tan be sabetz de cambiar», RAO 164.3) de Jordi de Sant Jordi, «Dompna gentil, vos m'enculpats a tort» (RAO 16.1) de Pau de Bellviure, així com el poema satíric de Pere Miquel Carbonell «Vos, en Galant, vergonya teniu poca» (RAO 30.8) i el cicle de Bernat del Bosc. Finalment, tenim coneixement com a mínim d'un maldit perdut de Romeu Llull, segons ens informa una rúbrica del manuscrit Jardinet d'Orats (Barcelona, Biblioteca Universitària, ms. 151, f. 35r.): "Cobles de Romeu Llull scusant-se d'un mal dit quere inculpat contra una dama».

\section{$\rightarrow$ Bibliografia citada}

ANGLADE, Joseph (ed.), 1926: Las flors del gay saber, Barcelona, Institut d'Estudis Catalans.

Aramon i Serra, Ramon (ed.), 1938: Cançoner dels Masdovelles, Barcelona, Institut d'Estudis Catalans, Biblioteca de Catalunya.

ARCHER, Robert, 1996a: «Tres "maldits" inéditos contra hombres», Revista de Filología Románica, 13, 107-121.

ARCHER, Robert, 1996b: «Aproximació al maldit», Actes del setè Colloqui d'Estudis Catalans a Nord-Amèrica, ed. August Bover i Font, Jaume Martí-Olivella i Mary Ann Newmann, Barcelona, Publicacions de l'Abadia de Montserrat, 21-35.

ArCher, Robert; RIQUer, Isabel de, 1998: Contra las mujeres: poemas medievales de rechazo y vituperio, Barcelona, Quaderns Crema.

AsPerti, Stefano, 2002: «Testi poetici volgari di propaganda politica (secoli XII e XIII)», $L a$ propaganda politica nel basso medioevo: atti del XXXVIII Convegno Storico Internazionale, Spoleto, Centro Italiano di studi sull'alto Medioevo, 533-559.

AsPerti, Stefano, 2005: «El sirventès i l'herència de Bertran de Born», Mot so razo, 4, 49-58.

Bertolucci Pizzorusso, Valeria, 1993: «Motivi e registri minoritari nella lirica d'amore galegoportoghese: la chanson de change», O Cantar dos 
Trovadores. Actas do Congreso celebrado en Santiago de Compostela entre os días 26 e 29 de abril de 1993, Santiago de Compostella, Xunta de Galicia, 109-120. Boutière, Jean; Schutz, Alexander Herman (eds.), 1950: Biographies des troubadours. Textes provençaux des XIII ${ }^{e}$ et XIV ${ }^{e}$ siècles publiés avec une introduction et des notes, Toulouse-París, Édouard Privat-Marcel Didier.

Bohigas, Pere (ed.), 200o: Ausiàs March, Poesies, Barcelona, Barcino.

CABRÉ, Miriam, 1999: «Du genre débat chez Cerverí de Girona», Il genere tenzone nelle letterature romanze delle Origini, ed. Matteo Pedronio i Antonio Stäuble, Ravenna, Longo, 363-377.

Cantavella, Rosanna. 1988-89: «Sobre el Maldit bendit de Cerverí», Llengua i literatura, 3, 7-40.

Casas Homs, Josep M. (ed.), 1956: Lluís d'Averçó, Torcimany, Barcelona, Consejo Superior de Investigaciones Científicas.

Casas Homs, Josep M. (ed.), 1969: Joan de Castellnou, Obras en prosa, Barcelona, Fundació Vives Casajuana.

GalmÉs, Santiago (ed.), 1935-54: Ramon Llull, Llibre d'Evast e Blanquerna, Barcelona, Barcino (Els Nostres Clàssics, 50-51, 58-59, 74, 75).

Gatien-Arnoult, M. (ed.), 1841-43: Guillem Molinier, Las flors del Gay Saber estier dichas las Leys d'amors, Tolosa de Llenguadoc, Bon et Privat.

GrIfOLL, Isabel, 2017: «Guillem de Berguedà: de la cançó satírica al sirventès», Occitània en Catalonha: de tempses novèls, de novèlas perspectiva. Actes de l'XIèn Congrès de l'Associacion Internacionala d'Estudis Occitans, ed. Aitor Carrera i Isabel Grifoll, Barcelona-Lleida, Generalitat de Catalunya, Departament de Cultura, Direcció General de Política Lingüística-Diputació de Lleida, 529-542.

Marshall, John H. (ed.), 1972: Ramon Vidal de Besalú, The 'Razos de trobar' of Raimon Vidal and associated texts, Londres, Oxford University Press.

Monson, Don Alfred, 1981: Les "Ensenhamens» occitans. Éssai de définition et de délimitation du genre, París, Klincksieck.

PAden, William D., 2000. «The System of Genres in Trobadour Lyric», Medieval Lyric: Genres in historical context, ed. William D. Paden, Urbana, Chicago, University of Illinois Press, 21-67.

BdT = Pillet, Alfred; Cartsens, Henry, 1968: Bibliographie der troubadours, Nova York, Burt Franklin.

RAO = PARRAMON, Jordi, 1992: Repertori de la poesia catalana medieval, Barcelona, Curial-Publicacions de l'Abadia de Montserrat.

RIEger, Angelica, 1992: «La mala canso de Gui d’Ussel, un exemple d'“intertextualité de pointe"», Contacts de langues, de civilizations et intertextualité, ed. Gérard Gouiran, Montpeller, Universtié PaulValery, vol. II, 1071-1088.
RIEGER, Dietmar, 1976: Gattungen und Gattungensbezeichnungen der Trobadorlyrik, Tübingen, Max Niemeyer Verlag.

Riquer, Isabel de, 1996: «Lo Canviador de Jordi de Sant Jordi: maldit», Boletín de la Real Academia de Buenas Letras de Barcelona, 45, 239-258.

RiQuer, Isabel de, 1996-1997: «La Mala Cansó provenzal, fuente del Maldit catalán», Revista de lenguas y literaturas catalana, gallega y vasca, 5 , 109-128.

Riquer, Isabel de, 2005: “"Mala domna" i "Dona de mal”: el rebuig de l'estimada infidel per part dels trobadors i dels poetes catalans de l'edat mitjana», Caplletra, 39, 141-169.

Riquer, Martín de (ed.), 1971: Guillem de Berguedà, L'Espluga de Francolí, Abadia de Poblet, 2 vols.

Riquer, Martín de (ed.), 1975: Los Trovadores, Barcelona, Ariel, 3 vols.

RiQuer, Martí de, 1986, «Las "coplas de la panadera" en Cataluña», Philologica Hispaniensa, ed. J. Fernández-Sevilla et. al., Madrid, Gredos, vol. III, 435-450.

RiQueR, Martín de (ed.), 1995: Vidas y retratos de trovadores, Barcelona, Galaxia Gutenberg.

Rodríguez RisQuete, Francisco J., 2002: «Del cercle literari del Príncep de Viana i unes poesies satíriques del Cançoner de Saragossa», Estudi General, 22, 365-391.

Torró, Jaume, 2009: Sis poetes del regnat d'Alfons el Magnànim, Barcelona, Barcino (Els Nostres Clàssics B, 29).

Thiolier-MÉJean, Suzanne, 1973: Les poésies satiriques et morales des troubadours du XIIe siècle à la fin $d u$ XIIIe siècle, París, Nizet.

Videira, Graça (ed.), 2002: Cantigas de Escárnio e Maldizer dos Trovadores e Jograis GalegoPortugueses, Lisboa, Estampa. 